\title{
Sharing is caring: How EM Sim Cases (EMSimCases.com) has created a collaborative simulation education culture in Canada
}

\author{
Kyla Caners, MD*; Jared Baylis ${ }^{\circ}, \mathrm{MD}^{\dagger}$; Christopher Heyd, MD*; Teresa Chan ${ }^{\circledR}, \mathrm{MD}, \mathrm{MHPE}^{*}$
}

\begin{abstract}
Free open access medical education (FOAM) resources in emergency medicine (EM) have grown exponentially in recent years. Within this movement, there are relatively few resources dedicated to simulation in EM. EM Sim Cases is a FOAM resource that was started in 2015 with the goal of creating a central database of simulation cases and scholarly articles that could be shared worldwide and thus reduce needless duplication of effort. Since 2015, EM Sim Cases has grown to have an annual average of 8,148 views per month from a total of 161 countries. It has an editorial team of 18 members as well as a leadership team of three. There is a robust, peer-reviewed case bank ranging in topic from neonatal resuscitation to end-of-life care as well as a number of simulation-relevant educational posts.
\end{abstract}

\section{RÉSUMÉ}

Le matériel didactique consultable sur la plateforme FOAM (Free Open Access Meducation : enseignement médical en libre accès) en médecine d'urgence (MU) a connu une croissance exponentielle au cours des dernières années. Toutefois, la documentation spécialisée sur la simulation est relativement peu abondante. C'est ainsi qu'EM Sim Cases, une ressource disponible sur FOAM, a vu le jour en 2015, dans I'optique que soit constituée une base de données centrale de cas simulés et d'articles savants mis à la disposition des utilisateurs partout dans le monde, d'où réduction de la redondance du travail. La base de données se développe depuis 2015 et atteint maintenant une moyenne annuelle de 8148 vues par mois, qui proviennent de 161 pays. L'équipe de rédaction compte 18 membres et l'équipe de direction, 3. EM Sim Cases est une banque robuste de cas évalués par les pairs, dont les sujets varient de la réanimation néonatale aux soins de fin de vie, et contient aussi un certain nombre de billets pédagogiques portant sur la simulation.

Keywords: Emergency medicine, free open access, medical education, simulation

\section{INTRODUCTION}

Most postgraduate emergency medicine (EM) programs in Canada describe having a simulation curriculum ${ }^{1}$ and yet, to our knowledge, these curricula largely act in isolation. Traditionally, simulation case banks and curricula have been compiled at local educational sites out of a need for simulation-based education. Often, these cases are designed such that they are only applicable to that local site and are not usually peer reviewed to ensure accuracy and rigour. Furthermore, the simulation curriculum design process is quite labor intensive, requiring expansive case development in addition to costly technical resources and simulation facilitation expertise. Not only does isolated simulation resource development result in cumulative wasted effort due to the inefficiency of creating separate case banks at each training program, but it furthers a silo mentality within simulation-based education.

The creation of EM Sim Cases was an attempt to shift culture within simulation education to a collaborative process where contributors are recognized for their work, the work is widely disseminated, and it is available

From the "Division of Emergency Medicine, Department of Medicine, McMaster University, Hamilton, ON; and the ${ }^{\dagger}$ Department of Emergency Medicine, University of British Columbia, Vancouver, BC.

Correspondence to: Dr. Jared Baylis, Kelowna General Hospital, 2268 Pandosy St, Kelowna, BC V1Y 1T2; Email: jbaylis@alumni.ubc.ca

(c) Canadian Association of Emergency Physicians 2020

CJEM 2020;22(6):819-821

DOI 10.1017/cem.2020.392 


\begin{tabular}{|c|c|}
\hline 1. People - Editorial board & $\begin{array}{l}\text { EM Sim Cases was initially founded by Dr. Kyla Caners and Dr. Martin Kuuskne with the guidance of a number } \\
\text { of highly active and experienced medical educators and simulation experts on the advisory board (Drs. } \\
\text { Jonathan Sherbino, Teresa Chan, Quang Ngo, Cheryl French, Andrew Hall, Chris Hicks, Alex Chorley, Brent } \\
\text { Thoma, Kaif Pardhan, and Catherine Grossman). } \\
\text { The advisory board has functioned as a team of collaborative experts shaping the direction of EM Sim Cases as } \\
\text { well as assisting with reviewing cases. Along the way more participants have been recruited to EM Sim } \\
\text { Cases in the form of more advisory board members (Drs. George Mastoras, Tamara McColl, and Michael } \\
\text { O'Brien), senior editors (Drs. Chris Heyd, Jared Baylis, Ashley Lubberdink, Sameer Sharif, and Ali Mulla) and } \\
\text { a junior editor (Dr. Anali Maneshi). }\end{array}$ \\
\hline \multirow[t]{3}{*}{$\begin{array}{l}\text { 2. Processes - Peer review } \\
\text { mechanism }\end{array}$} & $\begin{array}{l}\text { Our academic blog embraces an expert-driven, pre-publication, peer-review process for evaluation of the } \\
\text { simulation cases. Similar to other FOAM blogs that have risen to the call for ensuring high quality educational } \\
\text { content, EM Sim Cases is the first FOAM sim case repository to adopt a rigorous approach. } \\
\text { After each case is transcribed into the standardized EM Sim Cases template, it reviewed by at least } 2 \\
\text { reviewers, and reviewers are asked to comment upon } 4 \text { items: }\end{array}$ \\
\hline & $\begin{array}{l}\text { 1. Are there clear objectives? } \\
\text { 2. Does the case meet the objectives? } \\
\text { 3. Is the medical content sound? } \\
\text { 4. Does the case make sense in its flow? }\end{array}$ \\
\hline & $\begin{array}{l}\text { Feedback from the reviewers is synthesized by blog editors with discussion within the editorial team as needed } \\
\text { to build consensus on the best solutions to any issues identified during the review process. }\end{array}$ \\
\hline $\begin{array}{l}\text { 3. EM Sim Cases Simulation } \\
\text { Template }\end{array}$ & $\begin{array}{l}\text { A modifiable simulation template was produced that is freely accessible for anyone to use. This template has } \\
\text { multiple purposes; first, it is an open access template that scaffolds new simulation educators through case } \\
\text { construction, second it harmonizes the case submission process for the blog, and third it allows ease of } \\
\text { distribution of cases to multiple centres. }\end{array}$ \\
\hline
\end{tabular}

for all to use in a free, open access, and easily shareable format. It also sought to bring a level of scholarly rigour to the case development process with all cases having been trialled in a simulation setting and peer reviewed by two expert simulation educators. Recently, EM Sim Cases has been involved in efforts to distribute comprehensive simulation curricula, such as Queen's University "Nightmares Course." ${ }^{2}$ Additionally, it has led to several academic projects, such as the collaborative development of a national simulation template, based on the original EM Sim Cases template, through the Emergency Medicine Simulation Educators Research Collaborative.

\section{Rationale}

EM Sim Cases was created as a potential culture change medium within simulation-based education to foster collaboration and sharing of resources. This strategy was accomplished by curating peer-reviewed simulation cases, up-to-date simulation education articles, and a universal simulation case template accessible worldwide in a Free Open Access Medical education (FOAM) Webbased format.

\section{Description of Innovation}

EM Sim Cases was created in 2015 by K. Caners and M. Kuuskne. It has since grown to have 16 educational posts, 80 simulation cases, and 8,148 average monthly views from a total of 161 countries. Topics range from neonatal resuscitation to end-of-life care.

The case repository initially consisted mainly of cases written by the co-founders. The complete case collection has now published submissions from 32 individuals from 14 unique sites in three countries. A recent re-launch with a simulation-expert-developed, consensus-derived simulation template, a complete case series, and an online needs assessment occurred in the Fall of 2019.

EM Sim Cases is a robust, nontraditional repository of peer-reviewed, FOAM simulation material. It is unique in several ways, and in preparation for this manuscript, 
we embarked on an audit and reflective exercise to review our past and present procedures.

First, while other organizations have applied robust peer review processes in the FOAM world, ${ }^{3,4}$ peer review is still not the norm within open access education blogs, so the successful and sustained application of these processes is worth reporting.

Second, EM Sim Cases represents a case study for creating a repository for digital scholarship. Over time, it has come to be an internationally respected source of simulation cases, and has been cited in the peer reviewed literature frequently since its inception. ${ }^{5-8}$ Its cases are now used across multiple EM training sites in Canada and have been used to develop entire simulation curricula for training programs around the world. This demonstrates a successful facilitation of a culture of collaboration and sharing of intellectual content within simulation education.

Finally, EM Sim Cases has also become an increasingly popular publication venue for many simulation educators seeking to create peer reviewed works of digital scholarship.

\section{DISCUSSION}

In 2020, EM Sim Cases will have been in existence for 5 years. As such, the editorial board will be seeking to refresh and revive the scholarly repository. Future directions include initiating a leadership transition for the editorial board, conducting a needs assessment of the authors and audience in part to measure impact, creating and releasing a revised pan-Canadian EM simulation case template (with iterative design changes based on real-life use), and release of case bundles designed to address educational needs. Attempts will also be made to address some of the limitations of the EM Sim Cases resource including difficulties navigating the website, editorial delays, and a relative paucity of interprofessional content.

Our author group believes there are three key elements that likely have contributed to the growth of the
EM Sim Cases platform: a robust and active editorial board, a peer review mechanism for ensuring high quality content, and a common simulation template. These are detailed in Table 1.

\section{SUMMARY}

EM Sim Cases is a unique FOAM repository that was created out of a desire to reduce duplication of effort within simulation-based education. The website provides a peer-reviewed case bank and simulation-based articles that are used by simulation educators around the world.

Competing interests: None declared.

\section{REFERENCES}

1. Russell E, Hall AK, Hagel C, Petrosoniak A, Dagnone JD, Howes D. Simulation in Canadian postgraduate emergency medicine training - a national survey. CFEM 2018;20(1):132-41.

2. McMurray L, Hall AK, Rich J, Merchant S, Chaplin T. The nightmares course: a longitudinal, multidisciplinary, simulation-based curriculum to train and assess resident competence in resuscitation. 7 Grad Med Educ 2017;9(4):503-8.

3. Thoma B, Chan T, Desouza N, Lin M. Implementing peer review at an emergency medicine blog: bridging the gap between educators and clinical experts. CFEM 2015;17 (2):188-91.

4. Sidalak D, Purdy E, Luckett-Gatopoulos S, Murray H, Thoma B, Chan TM. Coached peer review: developing the next generation of authors. Acad Med 2017;92(2):201-4.

5. Gottlieb M, Chan TM, Sherbino J, Yarris L. Multiple wins: embracing technology to increase efficiency and maximize efforts. AEM Educ Train 2017;1(3):185-90.

6. Shappell E, Chan TM, Thoma B, et al. Crowdsourced curriculum development for online medical education. Cureus 2017;9(12):e1925.

7. Stuntz R, Clontz R. An evaluation of emergency medicine core content covered by free open access medical education resources. Ann Emerg Med 2016;67(5):649-53.e2.

8. Baylis J, Miloslavsky EM, Woods R, Chan TM. Conquering consultations: a guide to advances in the science of referralconsultation interactions for residency education. Ann Emerg Med 2019;74(1):119-25. 